\title{
Discontinuous Conduction Mode of Negative Output Elementary Circuit
}

Jung-Chien Li

Associate Professor, Department of Electrical Engineering, National Taiwan Ocean University, Keelung, Taiwan 202, R.O.C., B0088@mail.ntou.edu.tw

Han-Yang Chen

Graduate Student, Department of Electrical Engineering, National Taiwan Ocean University, Keelung, Taiwan 202, R.O.C.

Follow this and additional works at: https://jmstt.ntou.edu.tw/journal

Part of the Electrical and Computer Engineering Commons

\section{Recommended Citation}

Li, Jung-Chien and Chen, Han-Yang (2004) "Discontinuous Conduction Mode of Negative Output Elementary Circuit," Journal of Marine Science and Technology. Vol. 12: Iss. 2, Article 8.

DOI: $10.51400 / 2709-6998.2229$

Available at: https://jmstt.ntou.edu.tw/journal/vol12/iss2/8

This Research Article is brought to you for free and open access by Journal of Marine Science and Technology. It has been accepted for inclusion in Journal of Marine Science and Technology by an authorized editor of Journal of Marine Science and Technology. 


\title{
Short Paper
}

\section{DISCONTINUOUS CONDUCTION MODE OF NEGATIVE OUTPUT ELEMENTARY CIRCUIT}

\author{
Jung-Chien $\mathrm{Li}^{*}$ and Han-Yang Chen**
}

Key words: Negative output, discontinuous conduction mode.

\section{ABSTRACT}

The negative output elementary circuit operated in the discontinuous conduction mode is discussed. The voltage transfer gain of this dc-to-dc converter depends on switching frequency, conduction duty ratio, inductance, and load resistance. The condition for the discontinuous conduction mode is derived and verified. The variation ratio of the output voltage is also derived.

\section{INTRODUCTION}

The voltage lift technique is a popular method employed in the design of dc-to-dc converters. It can be used to design high voltage gain converters. The negative output super-lift converters operated in the continuous conduction mode (CCM) were proposed in [1]. The positive output super-lift converters operated in the CCM were proposed in [2]. The first stage of the negative output super-lift converter is called the elementary circuit, where only one inductor exists.

The operating of the negative output elementary circuit can be classified as the CCM [1] and the discontinuous conduction mode (DCM). In the CCM, the inductor current waveform is continuous. In the DCM, the inductor current waveform is discontinuous. We investigate the DCM of the negative output (N/O) elementary circuit in this paper.

\section{STEADY-STATE ANALYSIS}

The discontinuous operation of the N/O elementary circuit is shown in Fig. 1, where the inductor current waveform is shown in Fig. 2. The capacitance

Paper Submitted 02/23/04, Accepted 05/04/04. Author for Correspondence: Jung-Chien Li.E-mail: B0088@mail.ntou.edu.tw.

*Associate Professor, Department of Electrical Engineering, National Taiwan Ocean University, Keelung, Taiwan 202, R.O.C.

**Graduate Student, Department of Electrical Engineering, National Taiwan Ocean University, Keelung, Taiwan 202, R.O.C.

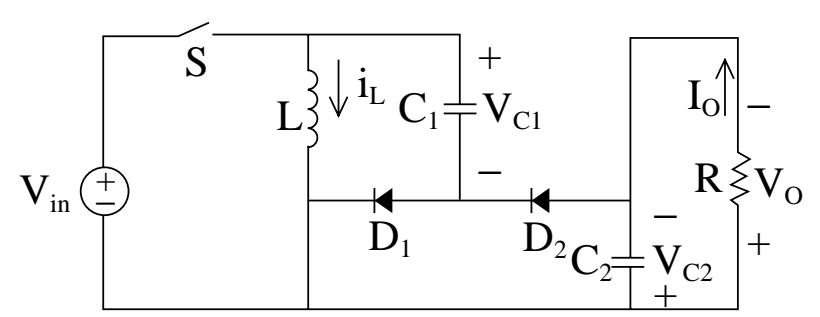

(a)

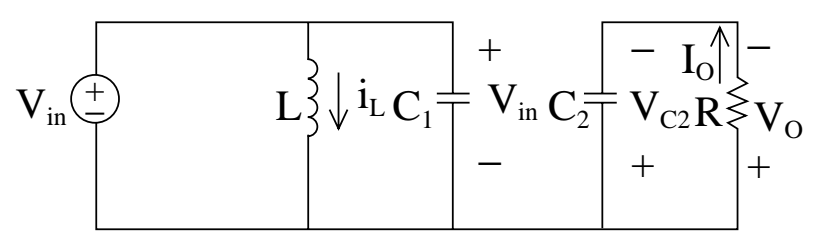

(b)

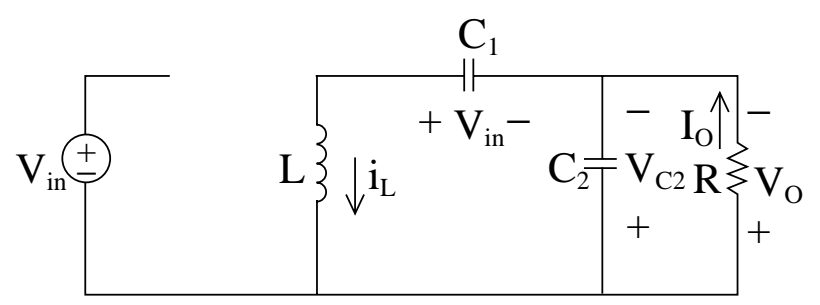

(c)

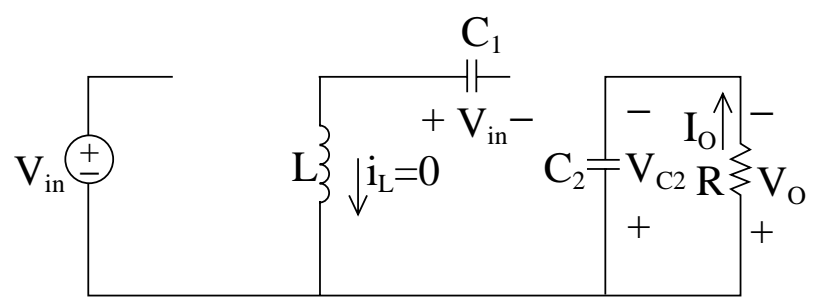

(d)

Fig. 1. N/O elementary circuit operated in the DCM (a) Circuit diagram (b) Equivalent circuit during switching-on $\left(D_{1}\right.$ on, $D_{2}$ off $)$ (c) Equivalent circuit during switching-off $\left(D_{1}\right.$ off, $D_{2}$ on) (d) Equivalent circuit during switching-off ( $D_{1}$ off, $D_{2}$ off $)$. 
values are large enough that the capacitor voltages can be assumed to be constant.

Consider Fig. 2, where the switching period is $T$ (and hence the switching frequency is $f=1 / T$ ) and the conduction duty ratio is $k$. During $0 \leq t \leq k T$, the equivalent circuit is Fig. 1(b), where the inductor current $i_{L}$ is increasing. During $k T \leq t \leq\left(k+k^{\prime}\right) T$, the equivalent circuit is Fig. 1(c), where the inductor current $i_{L}$ is decreasing. During $\left(k+k^{\prime}\right) T \leq t \leq T$, the equivalent circuit is Fig. 1(d), where the inductor current $i_{L}$ is zero. It can be observed from Fig. 2 that the DCM condition is

$$
k+k^{\prime}<1
$$

Consider Fig. 1(b), (c) and Fig. 2. During $0 \leq t \leq$ $k T, i_{L}$ increases with slope $V_{i n} / L$. During $k T \leq t \leq\left(k+k^{\prime}\right)$ $T, i_{L}$ decreases with slope $-\left(V_{o}-V_{i n}\right) / L$. Therefore,

$$
\Delta i_{L}=\frac{V_{\text {in }}}{L} k T=\frac{V_{o}-V_{\text {in }}}{L} k^{\prime} T
$$

Equation (2) can be simplified as

$$
k V_{\text {in }}=k^{\prime}\left(V_{o}-V_{\text {in }}\right)
$$

In the steady state, the average capacitor current is zero. Considering the current flowing through the capacitor $C_{2}$ in Fig. 1(b), (c), (d), we have

$$
k^{\prime} T\left(\frac{1}{2} \Delta i_{L}-I_{o}\right)=k T I_{o}+\left(1-k-k^{\prime}\right) T I_{o}=\left(1-k^{\prime}\right) T I_{o}
$$

Using $\Delta i_{L}=\left(V_{i n} / L\right) k T[$ from (2) $], I_{o}=V_{o} / R$ (where $R$ is the load resistance), and $T=1 / f$ in (4), we obtain

$$
\frac{1}{2} \frac{V_{i n} k^{\prime} k}{L f}=\frac{V_{o}}{R}
$$

Combining (3) and (5), we obtain

$$
k^{\prime}=\frac{k V_{\text {in }}}{V_{o}-V_{\text {in }}}=\frac{2 L f V_{o}}{V_{\text {in }} k R}
$$

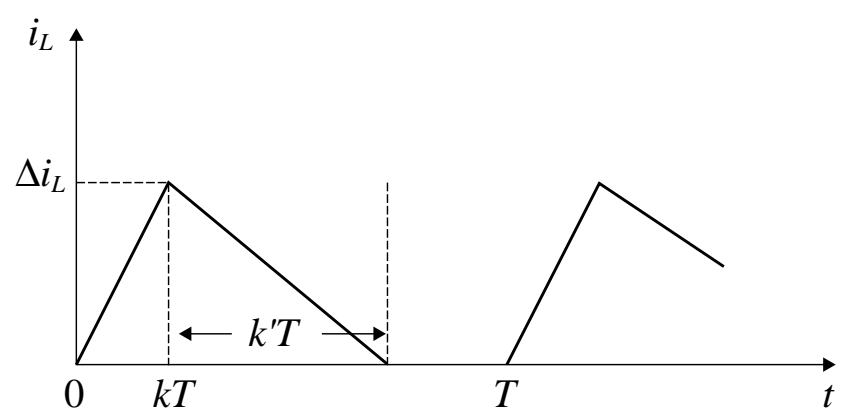

Fig. 2. Discontinuous inductor current waveform.
We define the voltage transfer gain $G=V_{o} / V_{\text {in }}$ in (6) and obtain

$$
k^{\prime}=\frac{k}{G-1}=\frac{2 L f G}{k R}
$$

Therefore,

$$
G^{2}-G-\frac{k^{2} R}{2 L f}=0
$$

Solving (8), we obtain the voltage transfer gain as

$$
G=\frac{1}{2}\left(1+\sqrt{1+2 k^{2} \frac{R}{L f}}\right)
$$

\section{DCM CONDITION AND ITS VERIFICATION}

The DCM condition is shown in (1), where $k^{\prime}=k$ / $(G-1)[$ from $(7)]$. Therefore,

$$
\begin{aligned}
& k+\frac{k}{G-1}<1 \Rightarrow \frac{k}{G-1}<1-k \Rightarrow \frac{G-1}{k}>\frac{1}{1-k} \\
& \Rightarrow G-1>\frac{k}{1-k} \Rightarrow G>1+\frac{k}{1-k} \Rightarrow G>\frac{1}{1-k}
\end{aligned}
$$

Substituting (9) into (10), we obtain

$$
\begin{aligned}
1 & +\sqrt{1+2 k^{2} \frac{R}{L f}}>\frac{2}{1-k} \Rightarrow 1+2 k^{2} \frac{R}{L f}>\left(\frac{2}{1-k}-1\right)^{2} \\
& =\left(\frac{1+k}{1-k}\right)^{2} \Rightarrow 2 k^{2} \frac{R}{f L}>\left(\frac{1+k}{1-k}\right)^{2}-1=\frac{4 k}{(1-k)^{2}} \\
& \Rightarrow \frac{R}{f L}>\frac{2}{k(1-k)^{2}}
\end{aligned}
$$

Equation (11) is the DCM condition, which can be verified from [1] as follows. Reference [1] gave the variation ratio of the inductor current $i_{L}$ (in the CCM) as

$$
\xi=\frac{\Delta i_{L} / 2}{I_{L}}=k(1-k)^{2} \frac{R}{2 f L}
$$

where $\xi<1$ in the CCM and $\xi>1$ in the DCM. Then the DCM condition is

$$
k(1-k)^{2} \frac{R}{2 f L}>1 \Rightarrow \frac{R}{f L}>\frac{2}{k(1-k)^{2}}
$$

which agrees with (11).

Both (11) and (13) can be rewritten as

$$
\frac{f L}{R}<g(k)
$$

where

$$
g(k)=\frac{1}{2} k(1-k)^{2}
$$

for which $0<k<1$. The maximum value of $g(k)$ can be derived as follows. 


$$
\begin{aligned}
g^{\prime}(k) & =\frac{1}{2}\left(3 k^{2}-4 k+1\right)=0 \Rightarrow k=\frac{1}{3} \Rightarrow g_{\max }(k)=g\left(\frac{1}{3}\right) \\
& =\frac{2}{27}
\end{aligned}
$$

Therefore, (14) can be illustrated in Fig. 3, where $k_{1}$ $<k<k_{2}$ corresponds to the DCM. However, if $\frac{f L}{R}>\frac{2}{27}$, then the converter always operates in the CCM.

\section{VARIATION RATIOS OF THE CAPACITOR VOLTAGES}

The peak to peak ripple voltage of the output voltage $v_{o}$ (which is also the capacitor voltage $v_{c 2}$ ) is [from Fig. 1(b) and Fig. 1(d)]

$$
\begin{aligned}
\Delta v_{o} & =\frac{\Delta Q}{C_{2}}=\frac{I_{o} k T+I_{o}\left(1-k-k^{\prime}\right) T}{C_{2}}=\frac{I_{o}\left(1-k^{\prime}\right) T}{C_{2}} \\
& =\frac{V_{o}\left(1-k^{\prime}\right)}{f R C_{2}}
\end{aligned}
$$

Therefore, the variation ratio of the output voltage $v_{o}$ is

$$
\varepsilon=\frac{\Delta v_{o} / 2}{V_{o}}=\frac{1-k^{\prime}}{2 f R C_{2}}
$$

where [using (7) and (9)]

$$
1-k^{\prime}=1-\frac{2 L f G}{k R}=1-\frac{L f}{k R}\left(1+\sqrt{1+2 k^{2} \frac{R}{L f}}\right)
$$

The peak to peak ripple voltage of the capacitor $C_{1}$ is [from Fig. 1(c), Fig. 2, and (2)]

$$
\begin{aligned}
\Delta v_{c 1} & =\frac{\Delta Q_{1}}{C_{1}}=\frac{1}{C_{1}} \times \frac{1}{2} \Delta i_{L} \times k^{\prime} T \\
& =\frac{1}{C_{1}} \times \frac{1}{2} \frac{V_{\text {in }}}{L} k T \times k^{\prime} T
\end{aligned}
$$

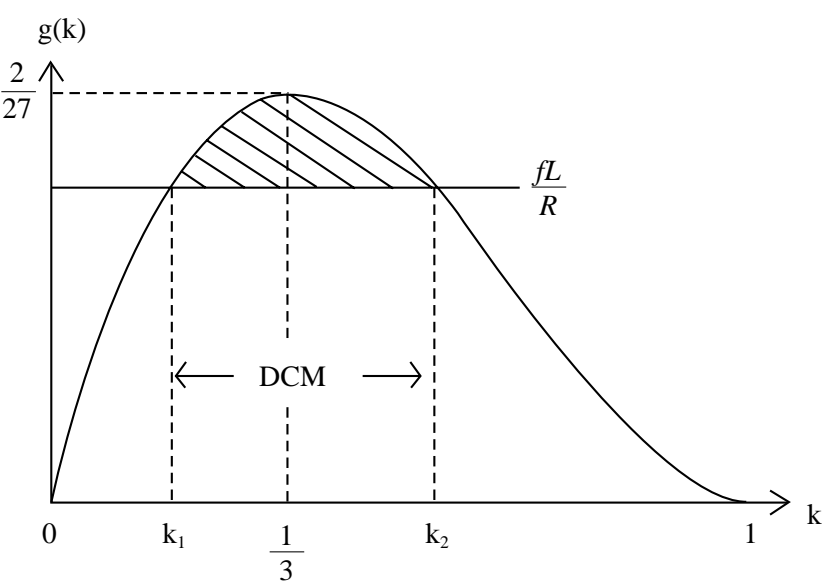

Fig. 3. Illustration of (14).
Since $V_{c 1}=V_{i n}$ [from Fig. 1(b)], the variation ratio of the capacitor voltage $v_{c 1}$ is [using (7) and (9)]

$$
\begin{aligned}
\varepsilon_{1} & =\frac{\Delta v_{c 1} / 2}{V_{c 1}}=\frac{\Delta v_{c 1}}{2 V_{i n}}=\frac{k k^{\prime}}{4 L C_{1} f^{2}}=\frac{k}{4 L C_{1} f^{2}} \frac{2 L f G}{k R} \\
= & \frac{G}{2 C_{1} f R}=\frac{1}{4 C_{1} f R}\left(1+\sqrt{1+2 k^{2} \frac{R}{L f}}\right)
\end{aligned}
$$

\section{SIMULATION AND EXPERIMENTAL RESULTS}

We choose $V_{\text {in }}=10 \mathrm{~V}, L=45 \mu \mathrm{H}, R=416.6 \Omega, C_{1}$ $=4.7 \mu \mathrm{F}, C_{2}=22 \mu \mathrm{F}, f=100 \mathrm{kHz}$, and $k=0.2$ for the circuit of Fig. 1(a). IsSpice simulation package and

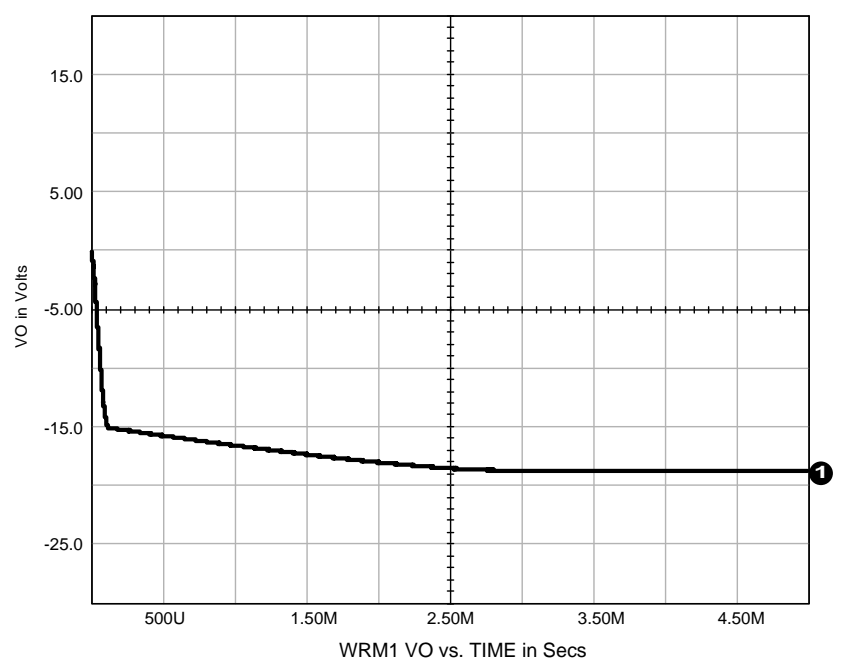

Fig. 4. Simulation result of the output voltage .

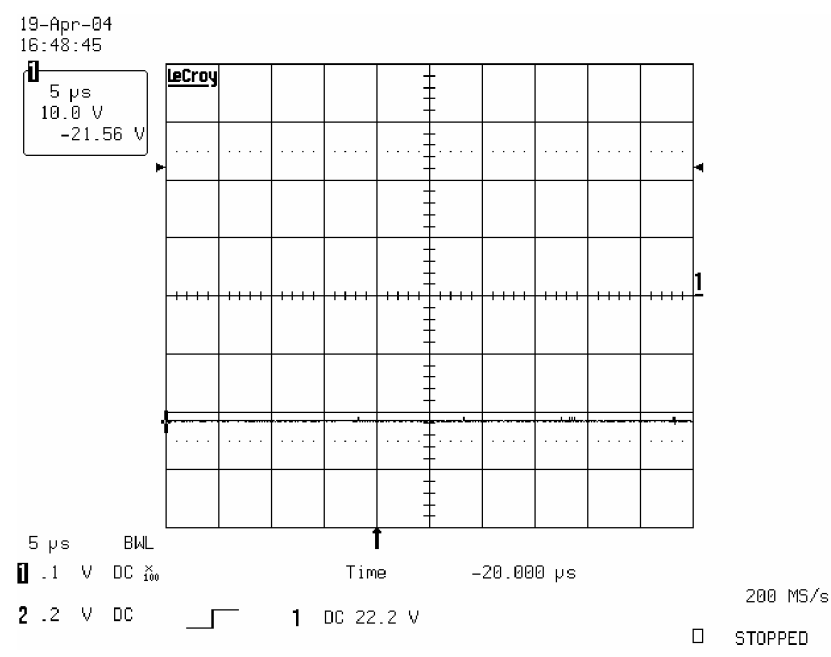

Fig. 5. Experimental result of the output voltage (time: $5 \mu \mathrm{s} / \mathrm{div}$, voltage: $10 \mathrm{~V} / \mathrm{div}$ ). 
LeCroy oscilloscope were applied to the circuit. The simulation and experimental results of the output voltage are shown in Fig. 4 and Fig. 5, respectively. The reader can check that both the simulation and experimental results agree with the analytical result of (9).

\section{CONCLUSIONS}

We have derived the voltage transfer gain for the negative output elementary circuit operated in the discontinuous conduction mode. Condition for the discontinuous conduction mode has been derived and verified. The converter can operate in the continuous conduction mode for any conduction duty ratio if the switching frequency or inductance is too large, or if the load resistance is too small. The variation ratios of the capacitor voltages have also been derived, and the corresponding capacitance value can be appropriately selected.

\section{NOMENCLATURE}

$k$ conduction duty ratio
$T \quad$ switching period

$f \quad$ switching frequency

$V_{\text {in }} \quad$ input voltage

$V_{o} \quad$ output voltage

$I_{o} \quad$ output current

$L$ inductance

$i_{L} \quad$ inductor current

$R \quad$ load resistance

$G \quad$ voltage transfer gain

$C_{1} \quad$ input capacitor

$C_{2} \quad$ output capacitor

$\varepsilon \quad$ variation ratio of the output voltage

$\varepsilon_{1} \quad$ variation ratio of the voltage across the capacitor $C_{1}$

\section{REFERENCES}

1. Luo, F.L. and Ye, H., "Negative Output Super-Lift Converters," IEEE Trans. Power Electron., Vol. 18, No. 5, pp. 1113-1121 (2003).

2. Luo, F.L. and Ye, H., "Positive Output Super-Lift Converters," IEEE Trans. Power Electron., Vol. 18, No. 1, pp. 105-113 (2003). 